DOI: 10.20472/IAC.2017.034.036

WUTTIGRAI NGAMSIRIJIT

National Institute of Development Administration, Thailand

\title{
AN ANALYTICS FRAMEWORK FOR IMPROVING PUBLIC SERVICE OPERATIONS AND PROCESSES TOWARDS TRANSPARENCY ISSUES
}

\begin{abstract}
:
It is critical for a public sector to raise awareness and fight against the corruption. Among many government projects, enhancing transparency through improving public service operations and processes can be seen as one of the solutions. This study presents the lesson learnt from the transparency project performed by government agencies including selection process and criteria, selected processes, attitudes towards the project, and various obstacles and limitations in deriving the right process. These findings are synthesized and an analytics framework of public service process selection for transparency is then proposed. Such framework incorporates data analytics methodologies and techniques so that it can be further developed to build transparency in today's digital age.
\end{abstract}

\section{Keywords:}

Service operations, Analytics, Transparency, Anti-corruption

JEL Classification: L32, O21, M29 


\section{Introduction}

In order to gain higher rank in Corruption Perceptions Index (CPI), a country needs to develop short-term potential program which is able to reduce or close the gaps in operations and processes leading to intended and unintended corruption (Kishor and Damania, 2007). Government must be able to incorporate data analytics methodologies and techniques as smartness has recently emerged as a desirable characteristic of government (Gil-Garcia et al, 2016).

In the following sections, they firstly present a descriptive overview of the national project on transparency in public sector. Secondly, the outcomes from action of the initiating and defining phases of the project are described. Thirdly, critical success factors of the transparency program are analyzed and, finally, an analytics framework for successful enhancement of transparency in public services is proposed so that an ongoing attempt to build transparency can be facilitated and achieved the desired results.

\section{National Project on Transparency in Public Sector}

The national project on transparency in public sector was launched and project missions and objectives were communicated to all government offices. This project employed bottom-up approach by responsible organizations to initiate their own implemented program based on a list of processes developed under Pubic sector Management Quality Award model. Committees were responsible for screening the proposed program through reviewing the proposals in aspects of its impact on the community and society, appropriateness of requested budget, program solvability, and scope of the program. After reviewing process, the suggestions on the program amendment and revision were given for final version of the proposal. The first phase of the project includes initiating and defining. The rest were conducted as second project phase. All government offices had equal project durations to complete, regardless of the scale of the program. Budgets had allocated to each of them based on their proposed and revised program. One year time scale for all offices to complete their program was designated. Thus, the offices must plan and deliver their program management by themselves. Again, monitoring progress, evaluating performance, and closing out the project were conducted by project management teams.

\section{Program selection process and criteria}

To tackle transparency issues from operational viewpoints, the choices of selected program must ensure targeted outcomes of the program. The agency informed all provincial offices the project' missions and objectives and assigned them making a 
proposal based on their own selection. This bottom-up approach was employed as there are such many possible process choices in public service operations associated with corruption in different aspects and extents. Thus, internal viewpoints and judgment were very crucial. Risk assessment of probability and impact $(\mathrm{P}-\mathrm{I})$ was used as broad criteria for offices in selecting the process.

Based on the selected process of which 77 provincial offices were selected, in overall, they were mainly coped with three transparency issues including personal judgment on approval, no specific process time, and obscure information conflicts. These emerged issues from the program selection process did not only represent certain related causes of non-transparency mainly from officers' viewpoints but were also found beneficial for further understandings on transparency in general. The following section describes how these three issues play a central role on corruption's loopholes.

\section{Personal judgment on reference and approval}

It is typically that there can be personal judgment involved in certain tasks of public affairs. Proof and evidence examination procedure sometimes follow with designated regulations which allows an existence of less objective judgment from authorized persons. For instances, applying for a license to carry a concealed handgun, it requires a reference and supporting document issued from village chief and headman. It is obvious that only physical assessment can be made but no behavioral one. This causes some difficulties to state intended or unintended action from the authorized persons. In despite, such less objective decision point can be pointed out in the work flow as most of tasks are performed in sequential manners, it is still not easy to make it explicit. These efforts may require redesigning work flow, working procedures, the roles and responsibilities, and even resources.

\section{No specific process time}

Most of public services have been continually improved in terms of service time, responsiveness and standard for civilian's satisfaction. Nevertheless, some of public services cannot specify the process standard time due to task dependency and complexity. For instances, to issue the title deed of agricultural land reform office, it takes longer processing time than ordinary one. In some cases, the request is suspended more than one year as the approval cannot be agreed upon related responsible offices. Such deference of approval process can lead to unfair consequences. Specifying standard process time for each task is helpful in investigating strangeness within the processes and reducing the opportunities for committing corruption (Kopits and Craig, 1998). 


\section{Obscure information conflicts}

In despite of specifying and standardizing the process time, some tasks can still remain being sources of corruption risk. It is likely that agreement on which specific information and evidences to be used in approval process among responsible offices is crucial, especially when it strings with the same piece of information and evidences (Bertot et al, 2010). In addition, renewal or newly introduction of certain civilian programs related to legislation adopted for such a long previous period can create some difficulties in tracking proofs and documents. No evidential documents can be shown due to no record or improper archival. Thus, this enhances the extent of corruption risk in particular public services. Certainly, corruption can be easily committed when there are obscure information conflicts and less tightened control mechanisms.

\section{Selected public service processes}

Among all selected processes from 77 provincial offices, the most of public offices prioritized the choices for selection by means of; corruption impact in terms of received interests and benefits upon swindlers in short term; corruption problems in current public issues or current works; corruption impact in terms of benefits upon communities and society in the lateral aspects and in long run.

\section{Actor' attitudes towards the program}

The process selection criteria were generally provided, which are probability and impact of corruption in the public services. Despite of further scrutinizing during program prioritization, in overall, the selected processes are not manifold to tackle all possible corruption risks existing in public services. Attitudes towards the program are found different among the actors. In contrast to the program selected based on swindlers' interests and benefits, when program chosen from current public issues or works and benefits upon the society, actors are likely to be more eagerly involved and participated in the program both as a person and a team. The proposed solutions seem to be more intrigued and straightforward. This can illustrate, in some extent, that there might have preferences in reducing corruption risk only in particular scale and scope. Corruption risks attached to interests and benefits are not likely to be effectively tackled by processoriented solutions. 


\section{Obstacles and limitations in deriving targeted and potential program}

Regardless of time constraints of the project, it is likely that identifying P-I criteria seems not to be adequate to derive targeted and potential program for transparency. In addition, most of provincial offices did not well deliberate the root causes of corruption risks, especially when selected from current works. They tended to mislead themselves for solutions towards operations and productivity improvement. In addition, they only concentrated on individual aspect of personal judgment on reference and approval, no specific process time, and obscure information conflicts, rather than combined them during selection of public service's process and formation of solutions. Consequently, only broad root cause of corruption risk was attained. There are only few broad understandings about corruption risk in public services.

The agency had communicated project description and formed a session of knowledge sharing among provincial offices which initially proposed exact or similar public service processes. Also, it opened a communication channel in form of help-desk for experts and consultants to counseling provincial offices on how to effectively select the processes during proposal development stage. In despite of the support, the understandings on corruption risk and its relationship to public service processes were not yet adequate by many provincial officers.

\section{Discussion: Critical success factors of the transparency program}

The results from the first two phases of this transparency project show that enhancing transparency in the public services through process-oriented perspective is quite challenging. Corruption risks exist in the processes but not all of them can be clearly identified due to task dependency and complexity. Consequently, the root causes cannot be disclosed and appropriate solutions cannot be obtained. Regarding to this, it is crucial to cope with it in more structured ways. Critical success factors include; (1) clear and proper scope of improvement; (2) clear understandings on corruption risk and related process choices to the risks; (3) multiple selection criteria; and (4) root cause analysis.

- Clear and proper scope of improvement: It is necessary to understand whether or not improving chosen processes, at the end, can result in achieving higher degree of transparency. Some corruption risks attached to interests and benefits are not likely to be effectively tackled by process-oriented solutions, it must be done by legal approaches which requires high cooperation and shared resources among government offices. The scope must be also defined in accordance with the level of corruption risk. Unlike process with high level of corruption risk requires longterm and dramatic changes; one with low level of corruption risk can conducted in small scale improvement and in short term manners. 
- Clear understandings on corruption risk and related process choices to the risks: Some corruption risk can be reduced by means of process improvement, e.g. standardizing process time, performing monitoring and control procedure, and managing information flow. Nevertheless, there still are confusion on process improvement and productivity improvement during the project. Productivity improvement has nothing to do with enhancing transparency and corruption risk.

- Multiple selection criteria: Selected process choice must be influenced by multiple criteria. The process choices are quantitatively evaluated against such criteria as probability criteria, impact criteria, and process improvement criteria. In terms of impact, it can include corruption impact in terms of received interests and benefits upon swindlers in short term; corruption problems in current public issues or current works; and corruption impact in terms of benefits upon communities and society in the lateral aspects and in long run. Process improvement criteria is one that focuses on areas of transparency enhancement including personal judgment on approval, no specific process time, and obscure information conflicts. Process selected must encompass all these areas to ensure the validity of the process.

- Root cause analysis: Root causes of corruption risk must be carefully analyzed. Simply said, they can typically start from the main causes of personal judgment on approval, no specific process time, and obscure information conflicts and breakdown for root causes. In order to successfully analyze the root cause, the work flow must be completely drawn and task dependency must be thoroughly identified.

\section{An analytics framework for improving public service operations and processes towards transparency issues}

The framework incorporates descriptive and predictive analytics for dealing with process selection (Mehta et al, 2017). Transparency can be obtained by improving ability to monitor and track the process performances. Visualization tools can facilitate the monitoring and tracking by incorporating demographic data of stakeholders, budgetary and financial data and key performance measures such as risk measures, productivity measures, etc. to acknowledge segments, outliers and anomalies from the processes and operations. Data items may be prioritized before taking into account in the descriptive analytics process (Pape, 2016).

As the risky processes are better identified and root causes can be determined as the results of descriptive analysis and data visualization, process selection criteria can then be expressed in more quantitative manner. Probability and impact of specific service operations can be examined by constructing predictive model. The outcomes of the model represent patterns of service performance (impact) regarding to its dependent 
variables and a number of cases for each pattern (probability). Therefore, process selection employing descriptive and predictive analytics can be more reliable and valid due to insights gained from the analytics. In addition, it is more transparent and less biased as data and information are inclusive.

\section{Conclusion}

The country's effort to fight against corruption is undergoing. The project has been facing with many challenges. The use of process perspectives in enhancing transparency in public services is considered good starting point. Bottom-up approach on process selection allows government offices looking more closely on corruption risk in the processes. In despite, the selected process were not much varied among the provincial offices and seemed not to be potential one in some provincial offices. The critical success factors derived from the study including clear and proper scope of improvement, clear understandings on corruption risk and related process choices to the risks, multiple selection criteria, and root cause analysis can be employed as a starting point and an analytics framework can be implemented to build transparency in public service operations and processes.

\section{References}

BERTOT, J. C., JAEGER, P. T. and GRIMES, J. M. (2010). Using ICTs to Create a Culture of Transparency: E-Government and Social Media as Openness and Anti-corruption Tools for Societies. Government information quarterly. 2010, Vol. 27, No. 3, p. 264-271.

GIL-GARCIA, J. R., ZHANG, J., \& PURON-CID, G. (2016). Conceptualizing Smartness in Government: An Integrative and Multi-dimensional View. Government Information Quarterly, Vol. 33, No. 3, p. 524534.

KISHOR, N. and DAMANIA, R. (2007) Crime and Justice in the Garden of Eden: Improving Governance and Reducing Corruption in the Forestry Sector. The Many Faces of Corruption. The World Bank, Washington, DC.

KOPITS, M. G. and CRAIG, M. J. (1998). Transparency in Government Operations (No. 158). International monetary fund.

MEHTA, P., BUTKEWITSCH-CHOZE, S. and SEAMAN, C. (2017). Data Analytics Framework for SemiContinuous Manufacturing Process-Implementation Vision with a Use Case. Journal of Manufacturing Systems, 2017, In press.

PAPE, T. (2016). Prioritising Data items for Business Analytics: Framework and Application to Human Resources. European Journal of Operational Research, 2016, Vol. 252, No. 2, p. 687-698. 